DP -1384

661995

\title{
EQUILIBRIUM DISTRIBUTION \\ OF URANYL NITRATE BETWEEN \\ NITRIC ACID AND 7.5 VOL \% TBP
}

M. C. THOMPSON,

B. E. MURPHREE, AND R. L. SHANKLE

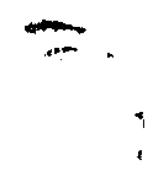


DP -1384

Distribution Category: UC-4

\section{EQUILIBRIUM DISTRIBUTION OF URANYL NITRATE BETWEEN NITRIC ACID AND 7.5 VOL \% TBP}

by

M. C. Thompson

B. E. Murphree*

R. L. Shankle**

Approved by

W. H. HaJe, Jr., Research Manager

Separations Chemistry Division

Publication Date: October 1975

* Present Address: Department of Chemical Engineering, University of Tennessee, Knoxville, Tennessee

** Present Address: Department of Chemistry, University of Tennessee, Knoxville, Tennessee.

E I DU PONT, DE NEMOURS AND COMPANY
SAVANNAH RIVER LABORATORY
AIKEN SOUTH CAROIINA 29801




\section{ABSTRACT}

The distribution of nitric acid and uranyl nitrate between aqueous solution and 7.5 vol \% tributyl phosphate in normal paraffin diluent was measured at 23,45 , and $60^{\circ} \mathrm{C}$. The data are consistent with behavior expected from theory and with previously published data. The data have been used to design a solvent extraction flowsheet for recovery of enriched uranium. 


\section{CONTENTS}

Introduction 5

Results and Discussion 5

Experimental Details 7

References 23

4. 


\section{LIST OF FIGURES}

1. Distribution of Uranyl Nitrate Between Aqueous Phase and 7.5 vol \% Tributyl Phosphate in n-Paraffin as a Function of Aqueous Nitric Acid and Uranyl Nitrate Concentrations at $23^{\circ} \mathrm{C}$.

2. Distribution of Uranyi Nitrate Between Aqueous Phase and 7.5 vol \% Tributyl Phosphate in n-Paraffin as a Function of Aqueous Nitric Acid and Uranyl Nitrate Concentrations at $45^{\circ} \mathrm{C}$.

3. Distribution of Nitric Acid Between Aqueous Phase and 7.5 vol \% Tributyl Phosphate in n-Paraffin as a Function of Aqueous Nitric Acid and Uranyl Nitrate Concentrations at $23^{\circ} \mathrm{C}$.

4. Distribution of Nitric Acid Between Aqueous Phase and 7.5 vol \% Tributyl Phosphate in n-Paraffin as a Function of Aqueous Nitric Acid and Uranyl Nitrate Concentrations at $45^{\circ} \mathrm{C}$.

5. Distribution Coefficient of Uranium as a Function of Aqueous Nitric Acid Concentration and Temperature at Low Uranium Concentrations.

\section{LIST OF TABLES}

1. Distribution of Nitric Acid and Uranyl Nitrate Between Aqueous Phase and 7.5 vol \% Tributyl Phosphate in $n$-Paraffin at $23^{\circ} \mathrm{C}$

2. Distribution of Nitric Acid and Uranyl Nitrate Between Aqueous Phase and 7.5 vol \% Tributyl Phosphate in n-Paraffin at $45^{\circ} \mathrm{C}$

3. Distribution of Nitric Acid and Uranyl Nitrate Between Aqueous Phase and 7.5 vol \% Tributyl Phosphate in n-Paraffin at $60^{\circ} \mathrm{C}$

4. Distribution of Nitric Acid and Uranyl Nitrate Between $\mathrm{Al}\left(\mathrm{NO}_{3}\right)_{3}$ Solutions and 7.5 vol \% Tributyl Phosphate in $n$-Paraffin at $23^{\circ} \mathrm{C}$

5. Distribution of Nitric Acid and Uranyl Nitrate Between $\mathrm{Al}\left(\mathrm{NO}_{3}\right)_{3}$ - Solutions and 7.5 vol \% Tributyl Phosphate in n-Paraffin at $45^{\circ} \mathrm{C}$

6. Analyses of Stock Solutions, 


\section{EQUILIBRIUM DISTRIBUTION OF URANYL NITRATE BETWEEN NITRIC ACID AND 7.5 VOL \% TBP}

\section{INTRODUCTION}

This study was conducted to provide fundamental data for designing a solvent extraction flowsheet for the recovery of enriched uranium using 7.5 vol $\%$ tri-n-butyl phosphate (TBP) in $n$-paraffin diluents. Although there have been many previous studies of the distribution of uranium between various concentrations of TBP and nitric acid or aluminum nitrate solutions, only one reports data on 7.5 vol $\%$ TBP. ' Since that study did not measure the effects of TBP saturation on the distribution of uranium and nitric acid, a study was initiated to provide this information over the practical range of temperatures and concentrations and thereby to provide a basis for the desired solvent extraction flowsheet for recovery of enriched uranium.

Distribution measurements in 7.5 vol $\%$ TBP were obtained for $0.1 \mathrm{M}-4.5 \mathrm{M}$ nitric acid and $0.005 \mathrm{M}-1.0 \mathrm{M}$ uranium in the initial aqueous phase at 23,45 , and $60^{\circ} \mathrm{C}$.

\section{RESULTS AND DISCUSSION}

Extraction of uranium and nitric acid into TBP can be represented by the following equations: ${ }^{2-7}$

$$
\begin{aligned}
& \mathrm{H}_{\mathrm{aq}}^{+}+\mathrm{NO}^{-} \mathrm{aq}+2 \mathrm{TBP} \text { org }=\mathrm{HNO}_{3}(\mathrm{TBP})_{2} \text { org } \\
& \mathrm{H}_{\mathrm{aq}}^{+}+\mathrm{NO}_{3}^{-} \mathrm{aq}+\mathrm{TBP} \text { org }=\left(\mathrm{HNO}_{3}\right) \mathrm{TBP} \text { org } \\
& 2 \mathrm{H}_{\mathrm{al}}^{+}+2 \mathrm{NO}_{3}^{-} \mathrm{aq}+\mathrm{TBP}_{\text {org }}=\left(\mathrm{HNO}_{3}\right)_{2 \mathrm{TBP}} \text { org } \\
& \mathrm{UO}_{2}\left(\mathrm{H}_{2} \mathrm{O}\right)_{6}^{++}+2 \mathrm{NO}_{3}^{-} \mathrm{aq}+2 \mathrm{TBP} \mathrm{org}_{4}= \\
& \mathrm{UO}_{2}\left(\mathrm{NO}_{3}\right)_{2}(\mathrm{TBP})_{2} \text { org }+6 \mathrm{H}_{2} \mathrm{O} \text { aq }
\end{aligned}
$$

Total acid in the organic phast is the sum of the amount in the wringus species and can be written as:

$$
\left.\left[1 \mathrm{AO} \mathrm{O}_{3}\left(\mathrm{TBP}^{\mathrm{C}}\right)_{2}\right]+\left[\left(\mathrm{HNO}_{3}\right) \mathrm{TBP}^{\prime}\right]+2 \mathrm{~d}\left(\mathrm{HNO}_{3}\right)_{2} \mathrm{TBP}\right]
$$


Concentrations of acid and uranium in the organic phase depend on the hydrogen ion, nitrate ion, and uranyl ion concentrations in the aqueous phase. Nitrate ion, originating both from the extracted species and from inextractable metal salts such as aluminum nitrate, increases the concentrations of extractable species in the organic phase by the 1 aw of mass action. ${ }^{7}$ The concentration of free TBP depends on the initial concentration in the diluent and the concentrations of the extracted species. Uranyl ion forms a stronger complex with TBP than does nitric acid, so when the two species are competing for TBP, uranyl will be complexed or can replace nitric acid in the organic phase.

The effects of nitric acid and uranyl nitrate on the extraction of each other into 7.5 vol $\%$ TBP in n-paraffin diluent and the effect of aluminum nitrate addition on the extraction of both species are shown in Tables 1-5. Some of the data are plotted in Figures 1-4. The organic uranium concentration increases rapidly as the aqueous acid concentration is increased from 0.1 to $4 \mathrm{M}$ at low $(<0.01 \mathrm{M})$ aqueous uranium concentration (Figure 1$)$. The organic uranium concentration also increases rapidly with addition of uranium in the aqueous phase until the organic phase is essentially saturated with uranium and nitric acid (i.e., little free TBP is left). The organic uranium concentration continues to increase with increasing aqueous uranium concentration, but it increases more slowly as nitric acid is replaced with uranium in the organic phase. The relationships are shown by Figures 1 and 3 for $23^{\circ} \mathrm{C}$ and Figures 2 and 4 for $45^{\circ} \mathrm{C}$.

Temperature affects the extractions in a complex manner. The equilibrium constant, $k$, of any reaction is related to temperature (T) according to:

$$
\ln k=-\frac{\Delta G^{\circ}}{R T}
$$

where

$$
\begin{aligned}
\Delta G^{\circ} & =\text { free energy } \\
R & =\text { gas constant } \\
T & =\text { temperature, }{ }^{\circ} \mathrm{K}
\end{aligned}
$$

For uranium extraction in the absence of nitric acid, $\Delta G^{\circ}$ does not change with temperature in the range 5 to $40^{\circ} \mathrm{C}^{8}$ and thus:

$\cdots$ -

$$
\frac{\ln \mathrm{k}_{\mathrm{T}_{2}}}{\ln \mathrm{k}_{\mathrm{T}_{1}}}=\frac{\mathrm{T}_{1}}{\mathrm{~T}_{2}}
$$$$
1
$$

The organic uranium concentration is directly proportional to the equilibrium constant, $h, \cdots$ that as the toperature increases the

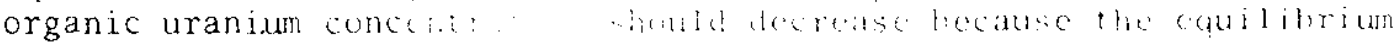

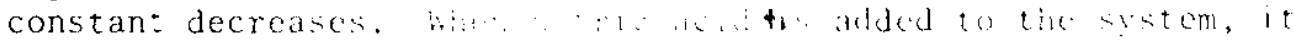


affects the magnitude of the organic uranium concentration through the common ion effect and also the aqueous activity coefficients. The organic uranium concentration still decreases with temperature in the presence of nitric acid, but the magnitude of the decrease is changed by the effect of nitric acid on activity coefficients in the aqueous phase.

Nitric acid distribution in the absence of uranium is not significantly affected by temperature. ${ }^{1}$ Figures 3 and 4 show the same nitric acid concentrations for 23 and $45^{\circ} \mathrm{C}$, respectively, when uranium concentrations are low. Adding uranium causes nitric acid to be "salted out" of the organic phase or replaced by uranium. Less uranium is in the organic phase at $45^{\circ} \mathrm{C}$ than at $23^{\circ} \mathrm{C}$, and thus more TBP can solvate nitric acid at the higher temperature. The organic acid concentration therefore increases at $45^{\circ} \mathrm{C}$ relative to $23^{\circ} \mathrm{C}$ for the same aqueous acid concentration (see Figures 3 and 4 at $\log$ aqueous uranium concentration $\geqslant-2$ ).

The data are shown to be consistent with previously published data ${ }^{2}$ in Figure 5 , where the $\log _{10}$ of uranium distribution coefficient, $\mathrm{D}_{\mathrm{O}} / \mathrm{a}$, is plotted as a function of nitric acid in the aqueous phase at two different temperatures. The uranium distribution coefficient was obtained from:

$$
\mathrm{D}_{\mathrm{O} / \mathrm{a}}=\frac{\mathrm{U}_{\mathrm{O}}}{\mathrm{U}_{\mathrm{a}}}
$$

where $U_{0}$ and $U_{a}$ are the concentrations of uranium in the organic and aqueous phases, respectively. Total uranium in aqueous and organic phases was $<0.03 \mathrm{M}$ and generally $\sim 0.01 \mathrm{M}$ for the previous work. ' The lowest total uranium concentrations were used from the data in Tables 2 and 3 . At these uranium concentrations, salting and saturation effects cause minor fluctuations in uranium distribution coefficients.

The two sets of data agree well even though the temperatures at which the different sets of data were taken vary somewhat. There appears to be slightly more scatter in the present data.

The two sets of data have been combined and smoothed to serve as a basis for design of a 7.5 vol $\%$ TBP solvent extraction flowsheet for recovery of enriched uranium, using computer programs which simulate operation of a mixer-settler. $\$, 10$

$$
\text { ini- }
$$

\section{EXPERIMENTAL DETAILS}

Tri-n-buty) phosphate (TBT) sas ragent grade. The diluent

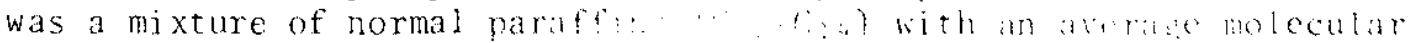

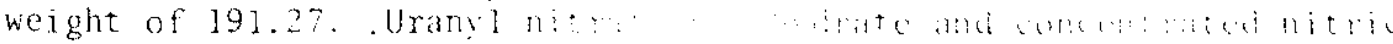
acid were reagent grade. 
The 7.5 vol $\%$ TBP was washed to remove small traces of monobutyl and dibutyl phosphate prior to equilibrations. Washing consisted of equal-volume washes with $2.5 \%$ sodium carbonate, $0.1 \mathrm{M}$ nitric acid, and $2.5 \%$ sodium carbonate followed by 4 to 5 equal-volume water washes. TBP was centrifuged for 4 to 5 minutes to remove excess water. Analysis of a sample of washed TBP-diluent solution showed 7.51 vol \% TBP. TBP was pre-equilibrated three times with equalvolumes of nitric acid of the same molarity as nitric acid used to make up the uranyl nitrate solutions. TBP was centrifuged again to remove entrained acid.

Nitric acid solutions were made from $15.7 \mathrm{M}$ concentrated acid. Stoek solutions of uranyl nitrate-nitric acid were made from reagentgrade concentrated nitric acid, uranyl nitrate hexahydrate, and distilled water.

Analyses of the solutions used are in Table 6. These stock solutions were used to prepare all intermediate solutions by appropriate mixing or diluting.

For equilibrations with aluminum nitrate as the salting agent, solutions were prepared from analyzed uranyl nitrate (1.95M) and aluminum nitrate $(2.47 \mathrm{M})$ solutions (Table 6 ) and reagent-grade concentrated nitric acid as described above for nitric acid-uranyl nitrate solutions.

Distribution measurements at room temperature $\left(23^{\circ} \mathrm{C} \pm 0.5^{\circ} \mathrm{C}\right)$ were made as follows: Equal ( $\sim 5 \mathrm{ml}$ ) volumes of 7.5 vol $\% \mathrm{TBP}$ and of the desired uranyl nitrate-nitric acid sample were placed in a 15-ml centrifuge cone and stirred on a vortex stirrer for 1-2 minutes. The phases were allowed to settle and centrifuged if necessary for complete separation.

Duplicate samples of the two separated phases were then analyzed for uranium, acid, and density. Distribution measurements at $45^{\circ} \mathrm{C}$ and $60^{\circ} \mathrm{C}$ were made similarly to the distributions at room temperature. A constant temperature bath was used to maintain the temperature within $\pm 1.0^{\circ} \mathrm{C}$. Samples were stirred for 1 to 2 minutes by an electric hand stirrer and allowed to settle. The aqueous and organic phases were then separated and analyzed.

... Uranium was determined cplorimetrically; acidity was determined by acid-base titration. Uranyl ion was complexed with fluoride ion to prevent interference during acidimetric titration. Organic uranium was determined after it was stripped into $0.5 \mathrm{M}$ sodium carbonate solution. The distribution data are summarized in Tables 1-5. Each value is an average of duplicate equilibrations. At very low $(00.01 \mathrm{~N})$ uranium concentrations, uranium was measured radiometrically with ${ }^{23} \mathrm{U}$ tracer. Uncertainties in analyses of uranium, acid, and density were cstimittod at $\pm 3 \%, \pm 5 \%$, and $\pm 5 \%$, respectively. 
TABLE 1

Distribution of Nitric Acid and Uranyl Nitrate Between Aqueous Phase and 7.5 vol \% Tributyl Phosphate in n-Paraffin at $23^{\circ} \mathrm{C}$

\begin{tabular}{|c|c|c|c|c|c|}
\hline \multicolumn{3}{|c|}{ Aqueous Phase } & \multicolumn{3}{|c|}{ Orgonic Phase } \\
\hline $\mathrm{HNO}_{3}, \mathrm{M}$ & $\mathrm{OO}_{2}\left(\mathrm{NO}_{3}\right)_{2}, \mathrm{M}$ & Density, $g / m \tau$ & $\mathrm{HNO}_{3}, \mathrm{M}$ & $\mathrm{UO}_{2}\left(\mathrm{NO}_{3}\right)_{2}, \mathrm{M}$ & Density, $g / m l$ \\
\hline 0.114 & 0.91 & 1.29 & 0.004 & 0.115 & 0.81 \\
\hline 0.108 & 0.42 & 1.14 & 0.003 & 0.077 & 0.80 \\
\hline 0.105 & 0.21 & 1.07 & 0.002 & 0.036 & 0.79 \\
\hline 0.103 & 0.073 & 1.03 & 0.001 & 0.0063 & 0.77 \\
\hline 0.100 & 0.037 & 1.01 & 0.001 & 0.0021 & 0.77 \\
\hline 0.100 & 0.0197 & 1.01 & $<0.001$ & 0.00074 & 0.77 \\
\hline $0.100^{\circ}$ & 0.0098 & 1.00 & $<0.001$ & 0.00031 & 0.77 \\
\hline 0.100 & 0.0050 & 1.00 & $<0.001$ & 0.00017 & 0.77 \\
\hline $0.110^{\mathrm{t}}$ & $2.1 \times 10^{-4}$ & - & $<0.001$ & $5.3 \times 10^{-6}$ & - \\
\hline 0.52 & 0.87 & 1.30 & 0.006 & 0.118 & 0.81 \\
\hline 0.51 & 0.68 & 1.24 & 0.006 & 0.111 & 0.81 \\
\hline 0.51 & 0.56 & 1.19 & 0.006 & 0.101 & 0.81 \\
\hline 0.51 & 0.41 & 1.15 & 0.007 & 0.091 & 0.80 \\
\hline 0.50 & 0.27 & 1.10 & 0.008 & 0.071 & 0.80 \\
\hline 0.50 & 0.192 & 1.08 & 0.008 & 0.056 & 0.79 \\
\hline 0.50 & 0.114 & 1.05 & 0.009 & 0.036 & 0.78 \\
\hline 0.50 & 0.059 & 1.03 & 0.009 & 0.022 & 0.78 \\
\hline 0.50 & 0.045 & 1.03 & 0.009 & 0.0150 & 0.78 \\
\hline 0.50 & 0.0150 & 1.02 & 0.009 & 0.0050 & 0.77 \\
\hline 0.50 & 0.0076 & 1.02 & 0.009 & 0.0023 & 0.77 \\
\hline 0.50 & 0.0046 & 1.02 & 0.009 & 0.00141 & 0.77 \\
\hline 1.01 & 0.55 & 1.21 & 0.011 & 0.110 & 0.81 \\
\hline 1.04 & 0.41 & 1.16 & 0.012 & 0.102 & 0.81 \\
\hline 1.03 & 0.26 & 1.12 & 0.014 & 0.087 & 0.80 \\
\hline 1.04 & 0.180 & 1.09 & 0.017 & 0.075 & 0.80 \\
\hline 1.02 & 0.095 & 1.06 & 0.020 & 0.055 & 0.79 \\
\hline 1.00 & 0.044 & 1.05 & 0.023 & 0.036 & 0.78 \\
\hline 1.0 .3 & 0.033 & 1.04 & 0.026 & 0.027 & 0.78 \\
\hline 1.03 & 0.021 & 1.04 & 0.029 & 0.0191 & 0.78 \\
\hline 1.04 & 0.0101 & 1.03 & 0.030 & 0.0105 & 0.78 \\
\hline 1.01 & 0.0044 & 1.03 & 0,032 & 0.0055 & 0.77 \\
\hline $0.95^{\mathrm{t}}$ & $1.10 \times 10^{-4}$ & - & 0.030 & $9.9 \times 10^{-5}$ & - \\
\hline 2.63 & 0.69 & 1.28 & 0,015 & 0.120 & 0.81 \\
\hline$\therefore \omega$. & $\therefore 5$ & 1.2 .4 & 0.018 & 0.116 & 0.81 \\
\hline$\therefore 1.4$ & $\because .10$ & 1.19 & 0.020 & 0.112 & 0.81 \\
\hline$\therefore$ (i); & $\because 24$ & 1.15 & 0.026 & 0.104 & 0.81 \\
\hline
\end{tabular}




\section{TABLE 1}

continued

\begin{tabular}{|c|c|c|c|c|c|c|}
\hline \multicolumn{3}{|c|}{ Aqueous Phase } & & \multicolumn{3}{|c|}{ Orgonic Phase } \\
\hline $\mathrm{HNO}_{3}, \mathrm{M}$ & $\mathrm{UO}_{2}\left(\mathrm{NO}_{3}\right)_{2}, \mathrm{M}$ & Density, $g / m l$ & & $\mathrm{HNO}_{3}, \mathrm{M}$ & $\mathrm{NO}_{2}\left(\mathrm{NO}_{3}\right)_{2}, \mathrm{M}$ & Density, $g / m i$ \\
\hline 2.02 & 0.076 & 1.09 & & 0.042 & 0.084 & 0.80 \\
\hline 1.96 & 0.030 & 1.08 & & 0.058 & 0.051 & 0.79 \\
\hline 2.02 & 0.020 & 1.07 & & 0.064 & 0.040 & 0.79 \\
\hline 1.98 & 0.0119 & 1.07 & & 0.074 & 0.028 & 0.78 \\
\hline 2.16 & 0.0055 & 1.07 & & 0.096 & 0.0152 & 0.79 \\
\hline 2.11 & 0.0025 & 1.06 & & 0.098 & 0.0079 & 0.78 \\
\hline $2.16^{t}$ & $4.8 \times 10^{-5}$ & - & & 0.105 & $1.63 \times 10^{-4}$ & - \\
\hline 2.85 & 0.54 & 1.26 & : & 0.022 & 0.118 & 0.81 \\
\hline 2.91 & 0.38 & 1.22 & & 0.028 & 0.114 & 0.81 \\
\hline 3.0 & 0.24 & 1.18 & & 0.035 & 0.108 & 0.81 \\
\hline 3.1 & 0.148 & 1.15 & & 0.042 & 0.099 & 0.80 \\
\hline 3.1 & 0.067 & 1.12 & & 0.062 & 0.088 & 0.80 \\
\hline 3.1 & 0.024 & 1.12 & & 0.092 & 0.060 & 0.80 \\
\hline 3.0 & 0.0143 & 1.10 & & 0.106 & 0.045 & 0.79 \\
\hline 3.1 & 0.0083 & 1.10 & & 0.122 & 0.032 & 0.78 \\
\hline 3.0 & 0.0033 & 1.10 & & 0.142 & 0.0158 & 0.78 \\
\hline 3.1 & 0.00162 & 1.10 & & 0.152 & 0.0087 & 0.78 \\
\hline $2.9^{t}$ & $3.6 \times 10^{-5}$ & - & & 0.150 & $1.87 \times 10^{-4}$ & - \\
\hline 4.2 & 0.39 & 1.26 & & 0.032 & 0.109 & 0.81 \\
\hline 4.2 & 0.24 & 1.21 & & 0.040 & 0.103 & 0.81 \\
\hline 4.2 & 0.152 & 1.18 & & 0.050 & 0.097 & 0.80 \\
\hline 4.1 & 0.067 & 1.16 & & 0.072 & 0.082 & 0.80 \\
\hline 4.1 & 0.021 & 1.14 & & 0.110 & 0.058 & 0.79 \\
\hline 4.1 & 0.0132 & 1.14 & & 0.125 & 0.047 & 0.79 \\
\hline 4.1 & 0.0070 & 1.13 & & 0.150 & 0.032 & 0.79 \\
\hline 4.1 & 0.0030 & 1.13 & & 0.370 & 0.018 & 0.78 \\
\hline $3.8^{t}$ & $2.7 \times 10^{-5}$ & - & & 0.200 & $1.90 \times 10^{-4}$ & - \\
\hline 4.5 & 0.39 & 1.27 & & 0.040 & 0.116 & 0.81 \\
\hline 4.4 & 0.147 & 1.19 & & 0.060 & 0.103 & 0.81 \\
\hline 4.3 & 0.0193 & 1.15 & & 0.130 & 0.059 & 0.79 \\
\hline$\cdots-4.4$ & 0.0066 & 1.14 & & 0.160 & 0.030 & 0.79 \\
\hline 4,4 & 0.0028 & 1.14 & & 0.185 & 0.0180 & 0.78 \\
\hline $4.5 t$ & $2.4 \times 10^{-5}$ & - & & 0.22 & $1.80 \times 10^{-6}$ & $=$ \\
\hline
\end{tabular}

t $2: 311+r a t+\cdots$ 


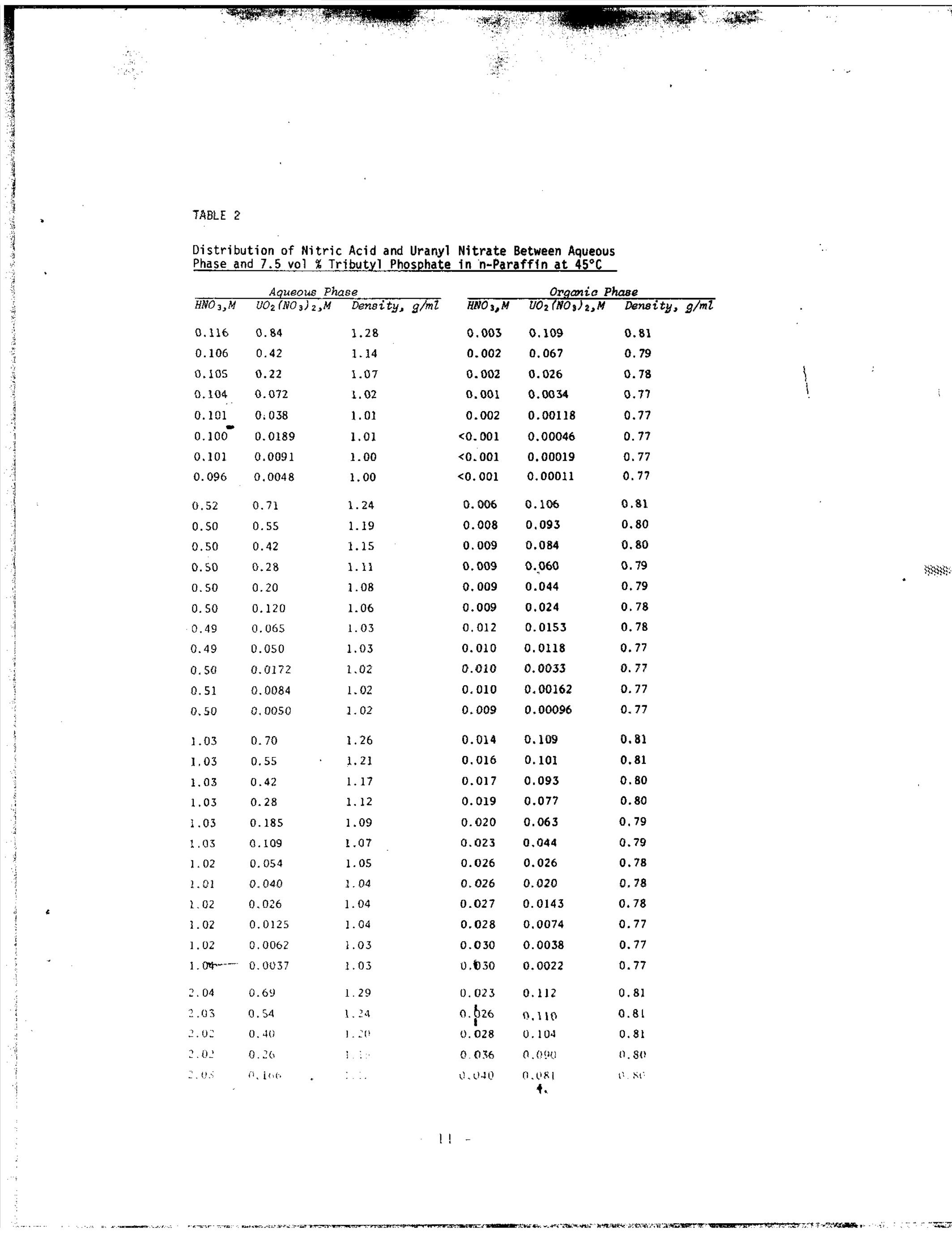




\section{TABLE 2}

continued

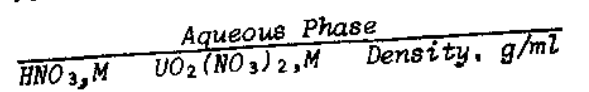

2.00

0.087

1.09

2.02

0.038

1.08

2.01

0.027

1.07

2.00

0.0169

1.07

2.00

2.00

0.0072

0.0033

0.00173

0.55

0.40

0.26

0.159

0.078

0.031

0.021

0.0052

0.0025

0.00137

0.39

0.25

0.162

0.075

0.028

0.0193

0.0112

0.0048

0.0022

0.00109

0.40

0.153

0.028

0.0108

4. 3

4,2

4.2

0.0045

0.0021

0.00105
3.06

1.06

1.06

1.27

1.22

1. 18

1.15

1.12

1.110

1.10

1.10

1.10

1.10

1.26

1. 21

1.18

1. 16

1.15

1.14

1.13

1.13

1.13

1.13

1.27

1. 19

1.15

1.14

1.14

1.14

1.14 $\frac{\text { Organic Phase }}{\mathrm{HNO}_{3}, \mathrm{M} \quad \mathrm{UO}_{2}\left(\mathrm{NO}_{3}\right)_{2}, \mathrm{M} \text { Density, } \mathrm{g} / \mathrm{ml}}$

$\begin{array}{lll}0.049 & 0.063 & 0.79\end{array}$

$\begin{array}{llll}0.066 & 0.044 & 0.79\end{array}$

$\begin{array}{llll}0.073 & 0.035 & 0.79\end{array}$

$\begin{array}{llll}0.078 & 0.023 & 0.78\end{array}$

$\begin{array}{llll}0.086 & 0.0125 & 0.78\end{array}$

$\begin{array}{llll}0.089 & 0.0063 & 0.78\end{array}$

$\begin{array}{lll}0.090 & 0.0032 & 0.78\end{array}$

$\begin{array}{lll}0.033 & 0.112 & 0.81\end{array}$

$\begin{array}{llll}0.039 & 0.105 & 0.81\end{array}$

$\begin{array}{llll}0.048 & 0.098 & 0.81\end{array}$

$\begin{array}{lll}0.058 & 0.089 & 0.80\end{array}$

$0.078: 0.071 \quad 0.80$

$0.098 \quad 0.051 \quad 0.79$

$\begin{array}{llll}0.118 & 0.038 & 0.79\end{array}$

$\begin{array}{llll}0.143 & 0.0158 & 0.78\end{array}$

$\begin{array}{llll}0.154 & 0.0076 & 0.78\end{array}$

$\begin{array}{llll}0.156 & 0.0038 & 0.78\end{array}$

$\begin{array}{lll}0.048 & 0.105 & 0.81\end{array}$

$\begin{array}{llll}0.057 & 0.100 & 0.80\end{array}$

$\begin{array}{lll}0.066 & 0.090 & 0.80\end{array}$

$\begin{array}{lll}0.093 & 0.074 & 0.80\end{array}$

$\begin{array}{lll}0.128 & 0.052 & 0.79\end{array}$

$\begin{array}{llll}0.146 & 0.041 & 0.79\end{array}$

$\begin{array}{llll}0.164 & 0.029 & 0.79\end{array}$

$\begin{array}{llll}0.181 & 0.0156 & 0.78\end{array}$

$\begin{array}{llll}0.198 & 0.0081 & 0.78\end{array}$

$\begin{array}{lll}0.20 & 0.0042 & 0.78\end{array}$

$\begin{array}{lll}0.05 & 0.105 & 0.81\end{array}$

$\begin{array}{lll}0.08 & 0.090 & 0.80\end{array}$

I

$\begin{array}{lll}0.14 & 0.050 & 0.79\end{array}$

$\begin{array}{lll}0.18 & 0.029 & 0.78\end{array}$

$\begin{array}{lll}0.20 & 0.0148 & 0.78\end{array}$

$\begin{array}{lll}0.20 & 0.0077 & 0.78\end{array}$

$\begin{array}{lll}0.20 & 0.0038 & 0.78\end{array}$

4. 
TABLE 3

Distribution of Nitric Acid and Urany? Nitrate Between Aqueous Phase and 7.5 vol \% Tributyl Phosphate in n-Paraffin at $60^{\circ} \mathrm{C}$

\begin{tabular}{lll} 
& \multicolumn{2}{c}{ Aqueous Phase } \\
\hline $\mathrm{HOO}_{3}, \mathrm{M}$ & $\mathrm{VO}_{2}\left(\mathrm{NO}_{3}\right)_{2, \mathrm{H}}$ & Density, $g / \mathrm{m}^{2}$ \\
0.105 & 0.87 & 1.29 \\
0.105 & 0.44 & 1.14 \\
0.103 & 0.22 & 1.07 \\
0.103 & 0.076 & 1.02 \\
0.104 & 0.039 & 1.01 \\
0.100 & 0.020 & 1.01 \\
0.102 & 0.0095 & 1.00 \\
0.100 & 0.0050 & 1.00 \\
4.6 & 0.42 & 1.27 \\
4.5 & 0.166 & 1.20 \\
4.4 & 0.035 & 1.15 \\
4.3 & 0.0153 & 1.14 \\
4.3 & 0.0065 & 1.14 \\
4.3 & 0.0031 & 1.14 \\
4.4 & 0.00158 & 1.14
\end{tabular}

\begin{tabular}{|c|c|c|}
\hline $\mathrm{BWO}_{3}, \mathrm{M}$ & $\mathrm{UO}_{2}\left(\mathrm{NO}_{3}\right)_{2}, M$ & Density, $g / m i$ \\
\hline 0.0038 & 0.101 & 0.81 \\
\hline 0.0021 & 0.057 & 0.79 \\
\hline 0.0011 & 0.021 & 0.78 \\
\hline 0.00048 & 0.0026 & 0.77 \\
\hline 0.00043 & 0.00069 & 0.77 \\
\hline 0.00054 & 0.00024 & 0.77 \\
\hline 0.00080 & 0.00008 & 0.77 \\
\hline 0.00085 & 0.00001 & 0.77 \\
\hline 0.071 & 0.098 & 0.80 \\
\hline 0.093 & 0.082 & 0.80 \\
\hline 0.156 & 0.044 & 0.79 \\
\hline 0.181 & 0.025 & 0.78 \\
\hline 0.20 & 0.0143 & 0.78 \\
\hline 0.21 & 0.0075 & 0.78 \\
\hline 0.22 & 0.0052 & 0.78 \\
\hline
\end{tabular}





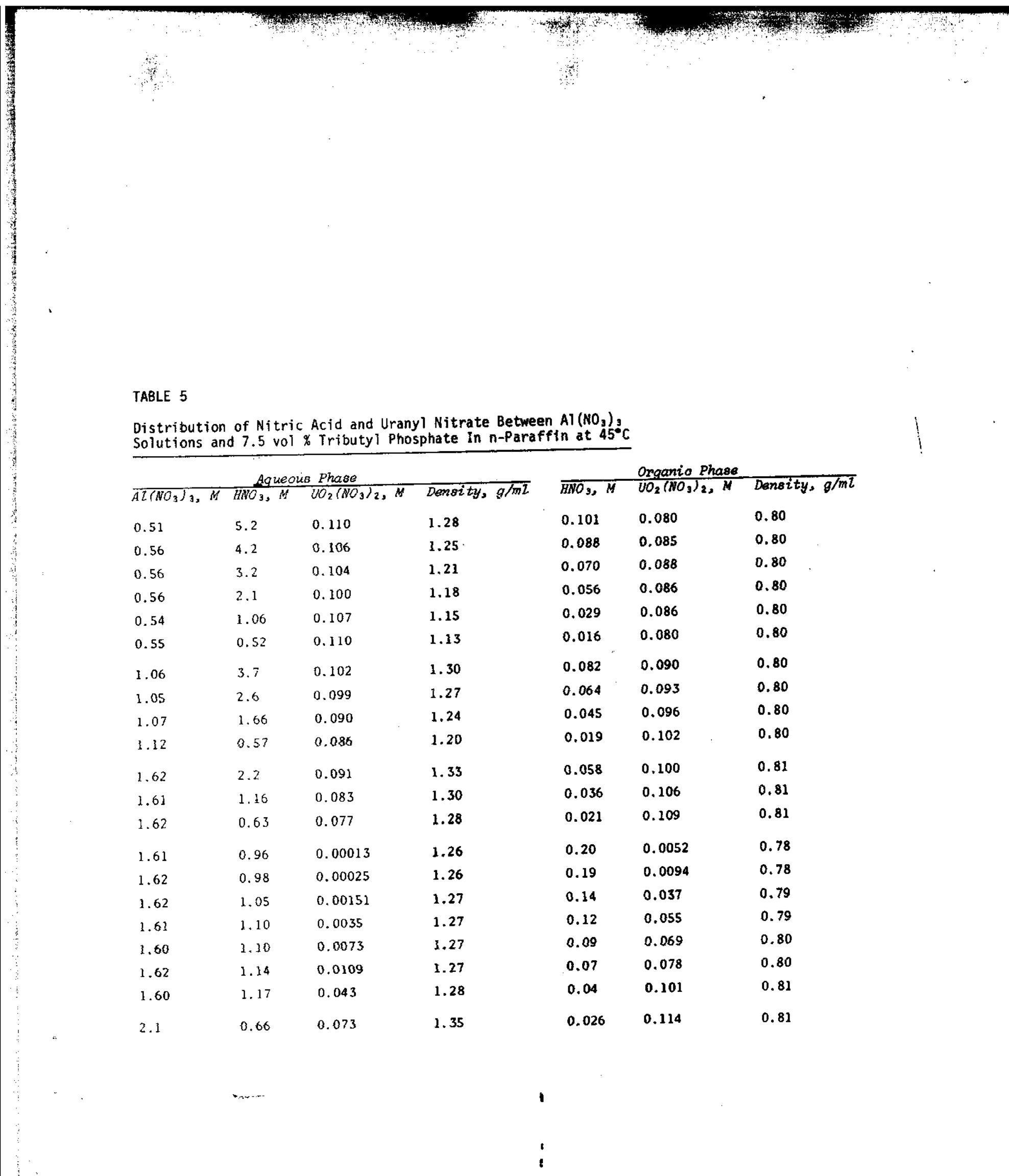

4. 
TABLE 6

\section{Analyses of Stock Solutions}

Stock Solutions

$0.1 \mathrm{M} \mathrm{HNO}_{3}$

$0.5 \mathrm{M} \mathrm{HNO}_{3}$

1. OM $\mathrm{HNO}_{3}$

$2 . \mathrm{OM} \mathrm{HNO}_{3}$

3. $\mathrm{OM} \mathrm{HNO}_{3}$

4. $0 \mathrm{M} \mathrm{HNO}_{3}$

$4.5 \mathrm{~N}^{2} \mathrm{NNO}_{3}$

$0.1 \mathrm{M} \mathrm{HNO}_{3}-1.0 \mathrm{MUO}_{2}\left(\mathrm{NO}_{3}\right)_{2}$

$0.5 \mathrm{M} \mathrm{HNO} 3-1.0 \mathrm{M} \mathrm{VO} 2\left(\mathrm{NO}_{3}\right)_{2}$

1. OM HNO $3-1.0 \mathrm{M} \mathrm{NO} 2\left(\mathrm{NO}_{3}\right)_{2}$

$2.0 \mathrm{M} \mathrm{HNO},-0.8 \mathrm{M} \mathrm{UO} \mathrm{U}_{2}\left(\mathrm{NO}_{3}\right)_{2}$

$3.0 \mathrm{MNO}_{3}-0.65 \mathrm{M} \mathrm{VO}_{2}\left(\mathrm{NO}_{3}\right)_{2}$

4. $\mathrm{OM} \mathrm{HNO}_{3}-0.50 \mathrm{M} \mathrm{NO} \mathrm{N}_{2}\left(\mathrm{NO}_{3}\right)_{2}$

$4.5 \mathrm{MHNO}-0.50 \mathrm{MUO}_{2}\left(\mathrm{NO}_{3}\right)_{2}$
$\mathrm{HNO}_{3}$

Molarity

0.097

0.50

1.01

2.0

3.0

4.0

4.5

0.13

0.53

0.98

2.1

2.8

4.0

4.6
$\mathrm{WO}_{2}\left(\mathrm{NO}_{3}\right)_{2}$

Molamity
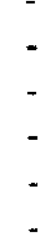

0.98

1.01

1.01

0.81

0.67

0.52

0.51 


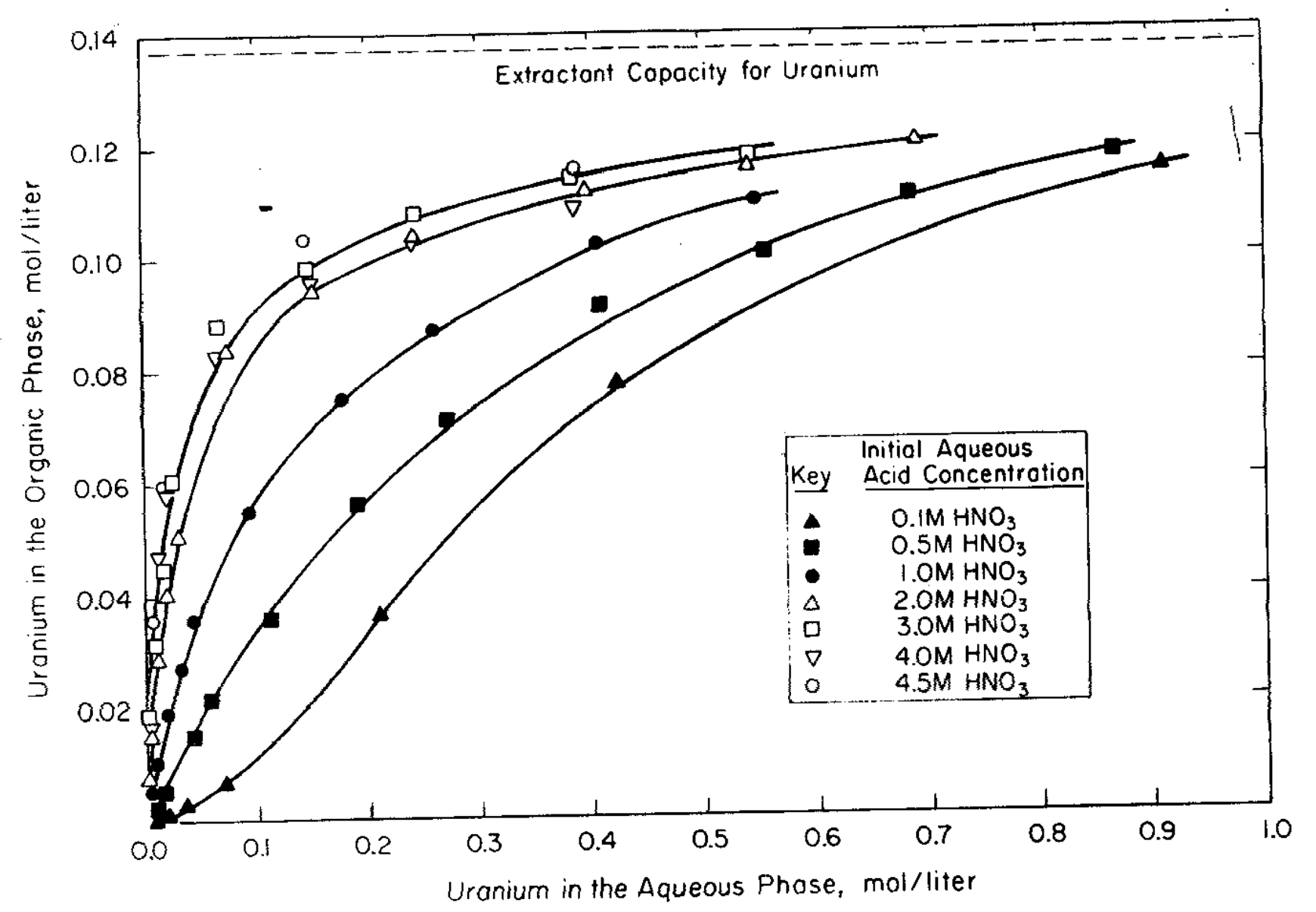

FIGURE 1. Distribution of Uranyl Nitrate Between Aqueous Phase and 7.5 vol \% Tributyl Phosphate in n-Paraffin as a Function of Aqueous Nitric Acid and Uranyl Nitrate Concentrations at $23^{\circ} \mathrm{C}$ 


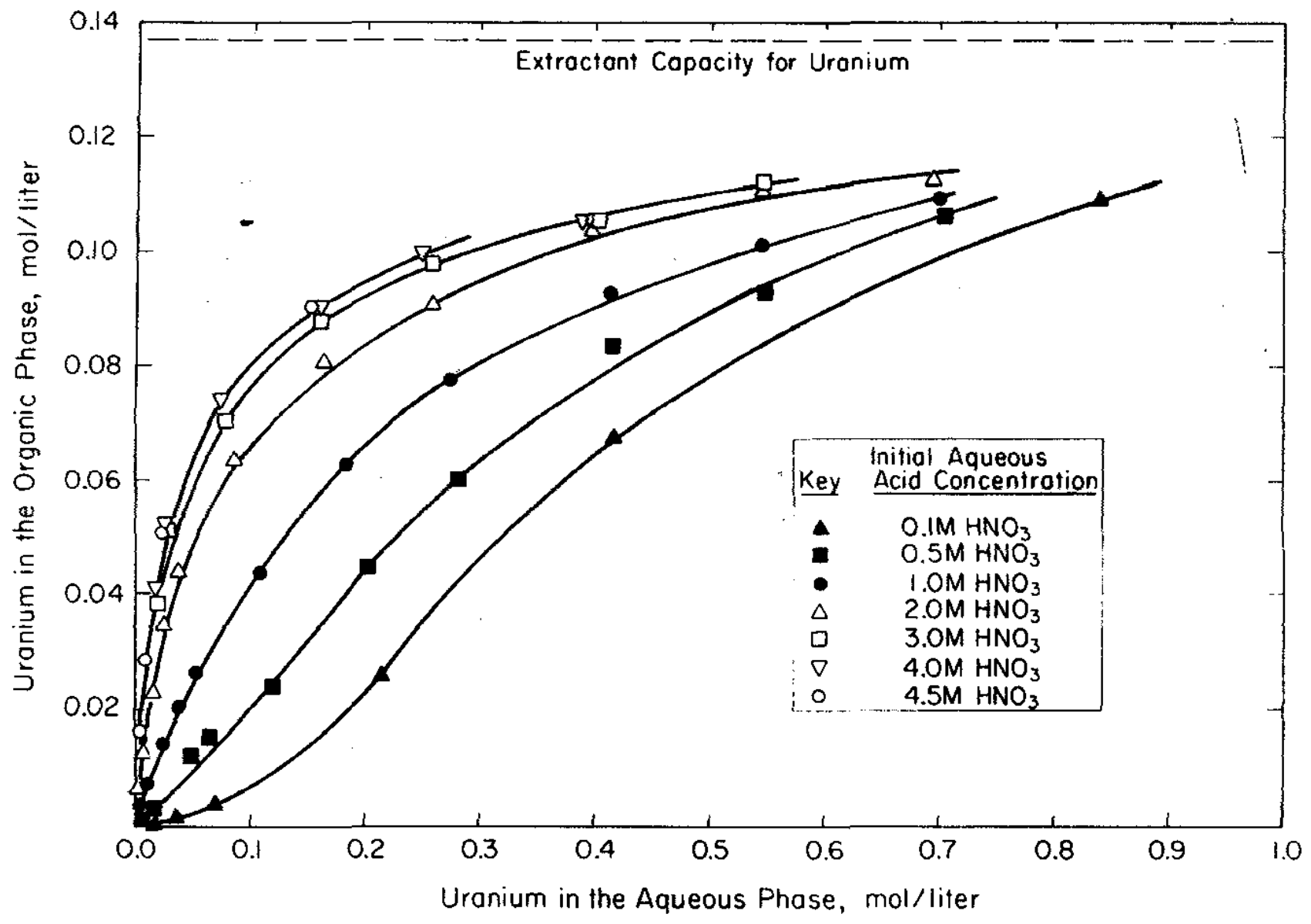

FIGURE 2. Distribution of Uranyl Nitrate in 7.5 vol \% Tributyl Phosphate Between Aqueous Phase and n-Paraffin as a Function of Aqueous Nitric Acid and Uranyl Nitrate Concentrations at $45^{\circ} \mathrm{C}$ 


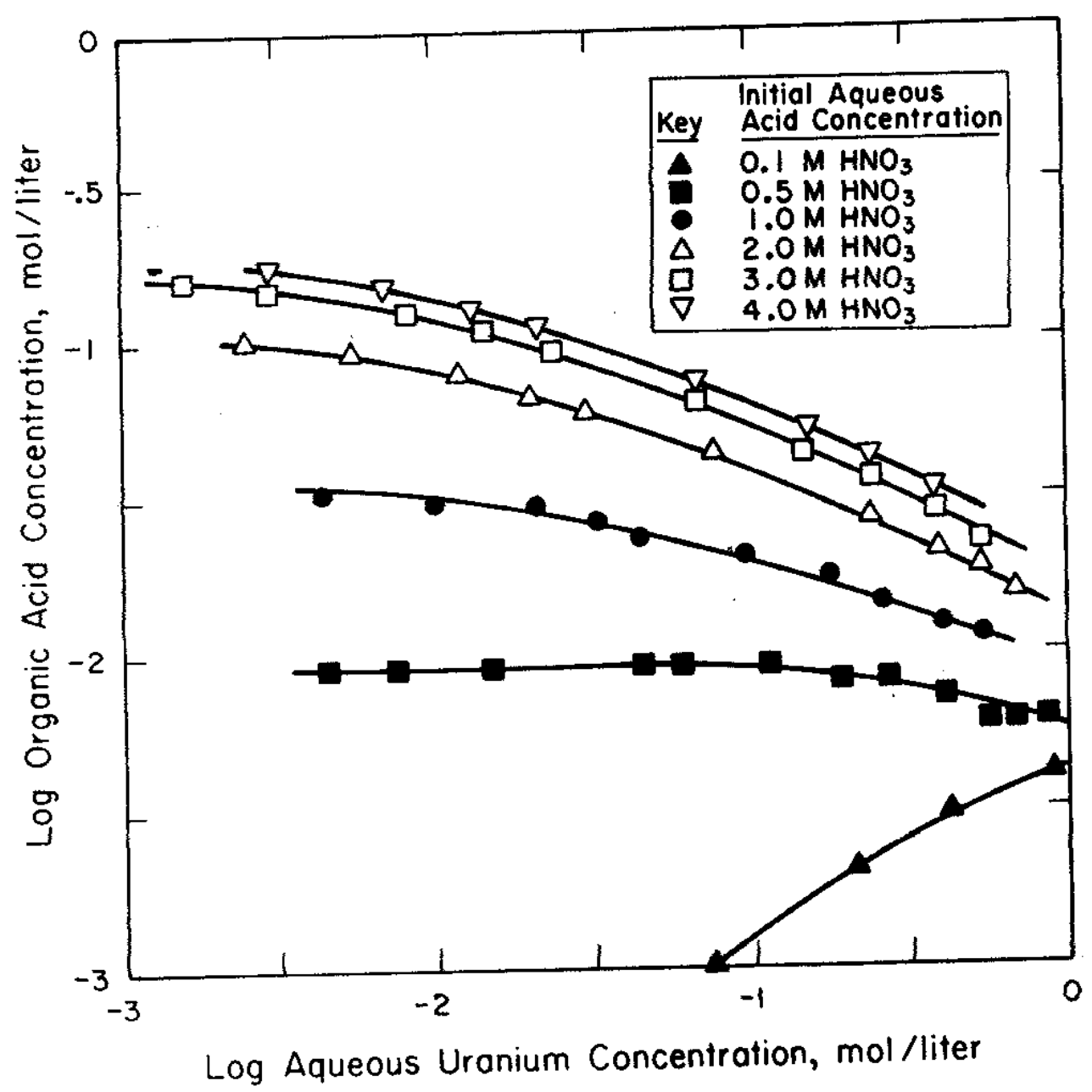

FIGURE 3. Distribution of Nitric Acid between Aqueous Phase and 7.5 vol \% Tributyl Phosphate in n-Paraffin as a Function of Aqueous Nitric Acid and Uranyl Nitrate Concentrations at $23^{\circ} \mathrm{C}$

4. 


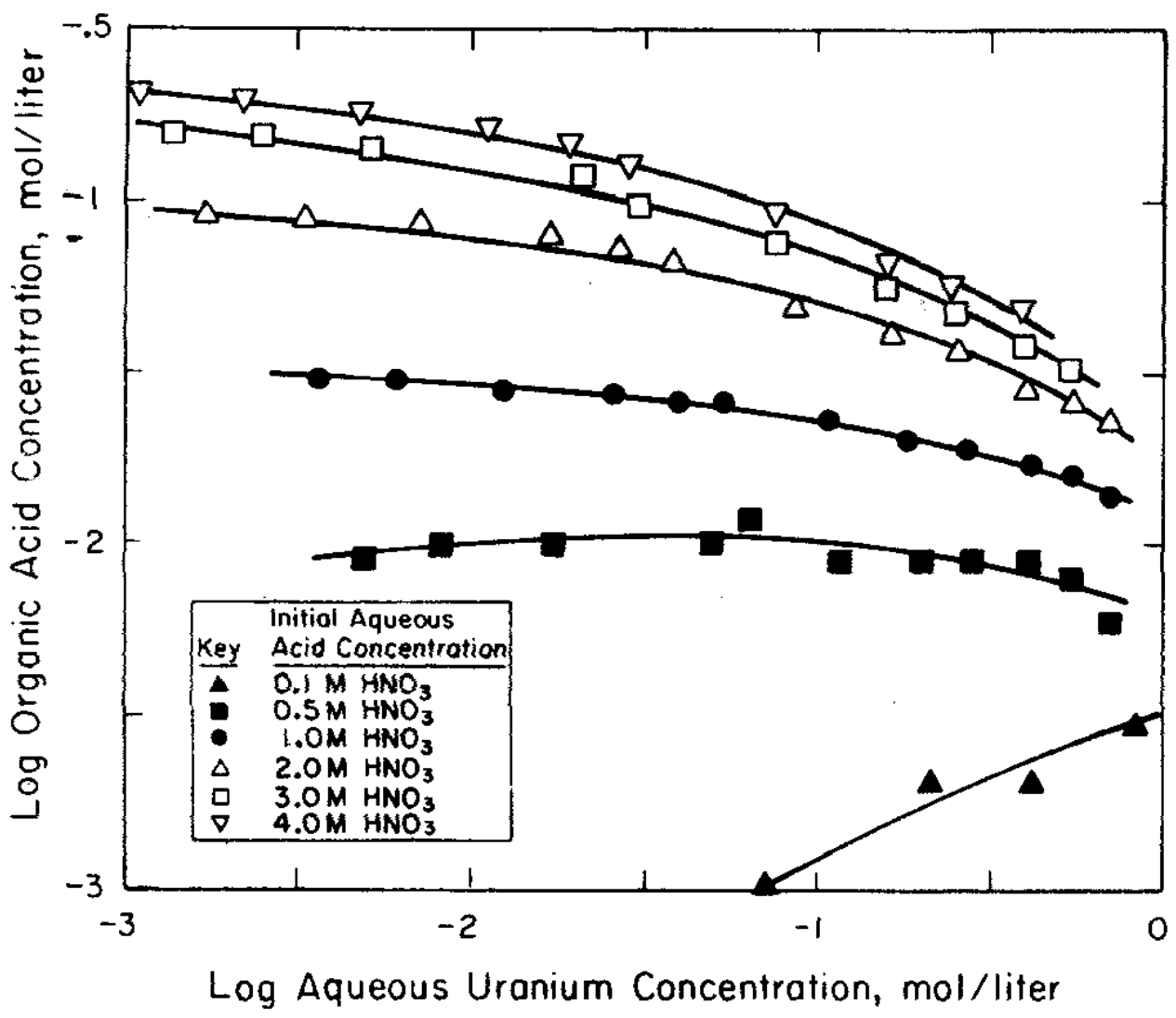

FIGURE 4. Distribution of Nitric Acid Between Aqueous Phase and 7.5 vol \% Tributyl Phosphate in n-Parraffin as a Function of Aqueous Nitric Acid and Uranyl Nitrate Concentrations at $45^{\circ} \mathrm{C}$

4. 

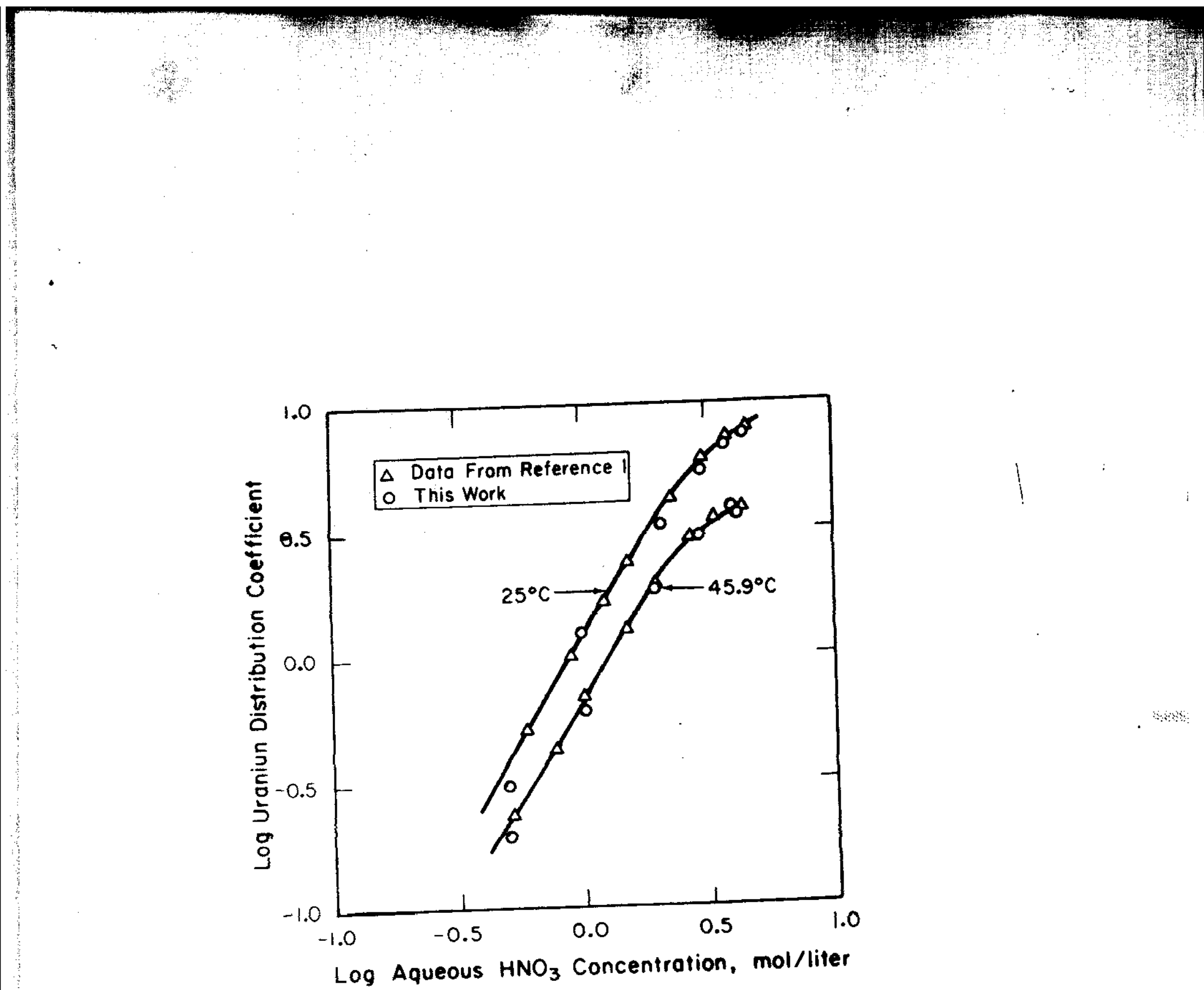

FIGURE 5. Distribution Coefficient of Uranium as a Function of Aqueous Nitric Acid Concentration and Temperature at Low Uranium Concentrations

4. 


\section{REFERENCES}

1. T. H. Sidda11, III, S. G. Parker, and W. E. Prout. Equilibrium Distribution Data for Purex and Similar Extraction Processes. USAEC Report DP-53, E. I. du Pont de Nemours \& Company, Savannah River Laboratory, Aiken, S. C. (1957).

2. W. Davis, Jr., J. Mrochek, and R. R. Judkins. "Thermodynamics of the Two-Phase System: Water-Uranyl Nitrate-Tributyl Phosphate-Amsco 125-82." J. Inorg. Nucl. Chem. 32, 1689 (1970).*

3. K. Alcock, S. S. Grimley, T. V. Healy, J. Kennedy, and H. A. C. McKay. "The Extraction of Nitrate by Tri-n-Butyl Phosphate (TBP). 1. The System TBP + Diluent $+\mathrm{H}_{2} \mathrm{O}+\mathrm{HNO}_{3} . "$ Trons. Faraday Soc. 52, 39 (1956).

4. T. V. Healy and H. A. C. McKay. "The Extraction of Nitrates by Tri-n-Butyl Phosphate (TBP).2. The Nature of the TBP Phase." Trans. Faraday Soc. 52, 633 (1956):

5. J. M. Fletcher and C. J. Hardy. "Extraction of Metal Nitrates by TBP.HNO ${ }_{3}$ " thuci. Sci. Eng. 16, 421 (1963).

6. A. M. Rozen, Z. I. Nikolotova, V. S. Markov, and E. G. Teterin. "Higher Solvates of Nitric Acid with Tributylphosphate." Soviet Radiochem. 14, 59 (1972).

7. Y. Marcus and A. S. Kertes. Ion Exchange and Solvent Extraction of Metal Complexes. p 669, Wiley-Interscience, London (1969).

8. Y. Marcus and 2. Kolarik. "Thermodynamics of Liquid-Liquid Distribution Reactions. 1. The Dioxouranium (VI) NitrateWater-Tri-n-Butyl Phosphate-n-Dodecane System." J. Chem. Eng.* Data 18, 155 (1973).

9. I. D. Eubanks and J. T. Lowe. "Steady-State Solvent Extraction Calculations for Curium Recovery." Ind. Eng. Chem., Proc. Desim * and Develop. 7, 172 (1968).

10. ..J. T. Lowe. "Calculation of The Transient Behavior of Solvent Extraction Processes." Ind. Eng. Chem. Proo. llesig; and * Develok. 7, 362 (1968). 